\title{
A TRADIÇÃo Do REGIONALISMO NA \\ LITERATURA BRASILEIRA: DO PITORESCO À \\ REALIZAÇÃO INVENTIVA
}

\section{The tradition of regionalism in Brazilian literature: from the picturesque to achieve inventive}

\author{
Humberto Hermenegildo de Araújo*
}

\section{O REgIONALISMO E A FoRMAÇÃo DO SiSTEMA LiTERÁRIO}

No primeiro volume de Formação da literatura brasileira, Antonio Candido afirma que o brasileirismo na expressão tem sido o elemento diferenciador a partir do qual a "teoria da literatura brasileira" estabelece os seus critérios de análise. Segundo ele, essa teoria surgiu inspirada no gosto pela expressão local e pelo sentimento do exótico, gosto que já se manifestava no poema Caramuru, de Santa Rita Durão, como um exemplo de celebração da flora tropical por meio do sistema erudito da poesia europeia. Nessa observação, o crítico investe na tese da dialética do universal e do particular como categoria decisiva na compreensão do processo formativo.

Em tal dialética, o gosto pela expressão local e pelo sentimento do exótico pode ser visto como elemento impulsionador do surgimento de uma tendência - o regionalismo - que se manifesta em vários momentos da história do sistema literário nacional, agregando ao seu conceito noções como "localismo", "pitoresco" e "bairrismo". Neste sentido, pode-se abordar a tradição regionalista como uma das dominantes construtivas do romance romântico brasileiro, da mesma forma que se pode recorrer a ela para compreender momentos decisivos da moderna literatura brasileira, de modo a promover releituras da permanência dessa tradição no sistema literário como um todo. 
Como um fator dinâmico, a noção de regionalismo reside no campo extraliterário e é construída historicamente, mas tem sido imprescindível à vida literária do país, com manifestações significativas nos dois momentos identificados por Antonio Candido (1980) como decisivos da literatura brasileira: o Romantismo e o Modernismo.

Ainda no primeiro volume do Formação, o seu autor dá destaque à figura do Frei Caneca como uma personagem cuja singularidade foi a maestria polêmica advinda da paixão liberal, no capítulo da "Época das Luzes", período correspondente ao fim do século XVIII e início do século XIX. Analisando os textos de Cartas de Pítia a Damão (1823) e os que foram publicados em O Tifis Pernambucano (1823-1824), observa que nele "[...] o bairrismo se configurava pela presença do seu traço característico: a animosidade, maior ou menor, em relação às outras regiões". Defensor do estado federativo que desobrigaria a subordinação das províncias ao governo central, Frei Caneca compreenderia o Brasil como "um grupo de nações diferentes". Entre essas nações brasileiras, enaltece Pernambuco como "pátria da liberdade" e "cidade do refúgio dos homens honrados, o baluarte da liberdade, o viveiro dos mártires brasileiros, a bússola das províncias árticas" (CANDIDO, 1975, p. 256-257).

Um dos objetivos de Antonio Candido é demonstrar, na leitura que faz dos textos de Frei Caneca, a "força da sua inteligência empenhada nas lutas sociais". Concluindo a leitura, afirma:

\begin{abstract}
Àquele tempo, no Brasil, abria-se uma fase que ia durar mais de um quarto de século, onde a literatura pública seria dominante e, nela, avultaria o estilo panfletário. Não poderíamos escolher disso exemplo melhor que o desse frade eminente, sem rigor excessivo na averiguação dos fatos, como convinha ao gênero, intransigente e sincero, de cultura larga e variada, que coroa a admirável linha, bem pernambucana, de paixão das luzes, germinada no Seminário de Olinda, no Areópago de Itambé, na Academia do Paraíso, e que constitui uma das manifestações mais altas da Ilustração no Brasil (CANDIDO, 1975, p. 260).
\end{abstract}

Como a sua preocupação é a organicidade do sistema e as soluções literárias com efeito duradouro, Antonio Candido valoriza no texto de Frei Caneca o momento em que o teórico do separatismo "[...] vai a extremos de irreverência, misturada a arroubos poéticos e a um nacionalismo pitoresco, análogo ao que os modernistas utilizarão, cem anos mais tarde" (CANDIDO, 1975, p. 258) ${ }^{1}$.

${ }^{1} \mathrm{Na}$ sua observação, o crítico demonstra a capacidade de apreender a força vital do sistema literário. Uma vez consolidada, a tradição renderia soluções de continuidade como a do "princípio da causalidade interna" identificado na moderna literatura brasileira (Cf. CANDIDO, 
Já no segundo volume do Formação, o regionalismo aparece na leitura realizada sobre Franklin Távora, considerado o primeiro "romancista do Nordeste". No capítulo "A corte e a província", Antonio Candido (1975, p. 298) ressalta "a diversidade que presidiu à formação e desenvolvimento da nossa cultura", graças ao processo de colonização em núcleos separados, não obstante a unidade política ${ }^{2}$. No caso específico do espaço geográfico e político que veio a se denominar "Nordeste" posteriormente, o sentimento regionalista encontrou uma expressão típica na Confederação do Equador e ganhou ilustração no romance romântico de Franklin Távora. Tal sentimento atravessa toda a história do sistema literário brasileiro que corresponde ao Romantismo até a formação da moderna tradição literária, de que fazem parte o "romance nordestino" e a obra de Gilberto Freyre.

Trata-se de um processo histórico dentro do qual há continuidades e rupturas, com implicações que extrapolam os limites do sistema literário propriamente dito. Assim, mesmo que Gilberto Freyre, por exemplo, não reconhecesse uma continuidade entre a perspectiva de Franklin Távora e a sua, a situação histórica da região impele o estabelecimento de relações entre as duas perspectivas como tendências presentes em dois momentos decisivos do sistema literário. Ambos responderam, a exemplo de Frei Caneca, a questões políticas das suas épocas, entendendo-se aquelas questões como motivadoras das suas demonstrações de empenho nas lutas sociais.

Tal peculiaridade é geradora de contradições, como aquela percebida, na análise, como um desvio promovido por Franklin Távora no projeto romântico: "Desvio evidente que, levando-o a dissociar o que era uno e fazer de características regionais princípio de independência, traía de certo modo a grande tarefa romântica de definir uma literatura nacional" (CANDIDO, 1975, p. 299) ${ }^{3}$.

1987). Mas a possibilidade de coincidências determinadas pela apreensão da realidade do país está implicada ao longo de todo o processo formativo, como sugere uma referência a Macunaíma, ao final do trecho citado, iluminando a leitura com a função de demonstrar o quanto o Frei Caneca foi capaz de promover uma irreverência "que bordeja a incredulidade" no "trecho movimentado onde o Brasil se transfigura" (CANDIDO, 1975, p. 259).

${ }^{2}$ A esse respeito, Evaldo Cabral de Mello (2001) aponta para a mística unitária do Império como um fator homogeneizador da nação, mística que se concretizou em atos administrativos contra os quais reagiram os surtos regionalistas.

${ }^{3}$ Parecem também contraditórias as reivindicações de Gilberto Freyre quanto à primazia de uma cultura regional em torno de Pernambuco, no momento em que se dava um amplo debate em torno da identidade nacional promovida pelo Modernismo e com eixo na brasilidade. A problemática referida tem sido analisada em estudos que, a exemplo de Azevêdo (1984), D'Andrea (1992) e Pallares-Burque (2005), analisam a participação do autor pernambucano no movimento cultural brasileiro. 
A tarefa romântica incluía, nos temas considerados nacionais, a celebração da natureza e o interesse por costumes e regióes. Contextualizados inicialmente na voga do indianismo, esses temas exprimiam o desejo de individuação nacional, que corresponderia ao desejo de individuação pessoal. Segundo Antonio Candido, o "único" revocava o "perene" do Arcadismo. Mas, como contrapeso do individualismo lírico, o romance permitiu à imaginação criadora a apreensão do cotidiano e a descrição objetiva da vida social. Nessa linha, os romances de costumes e o romance regional aparecem dentro de um projeto nacionalista: verdadeira forma de pesquisa e descoberta do país.

Quando analisa os temas citados, Antonio Candido identifica o problema da expressão literária adequada às direções tomadas pelo romance, conforme aparece no seguinte trecho:

[...] a língua e os costumes descritos eram próximos dos da cidade, apresentando difícil problema de estilização; de respeito a uma realidade que não se podia fantasiar tão livremente quanto a do índio e que, não tendo nenhum Chateaubriand para modelo, dependia do esforço criador dos escritores daqui. A obtenção da verossimilhança era, neste caso mais difícil, pois o original estava ao alcance do leitor. Daí a ambigüidade que desde o início marcou o nosso regionalismo; e que, levando o escritor a oscilar entre a fantasia e a fidelidade ao observado, acabou paradoxalmente por tornar artificial o gênero baseado na realidade mais geral e de certo modo mais própria do país (CANDIDO, 1975, p. 116, grifos do autor).

Na leitura apresentada, o regionalismo é visto como um fator decisivo de autonomia literária e importante contrapeso realista, uma vez que implicava esforço pessoal de estilização e grande quota de observação, traço que é comparado ao indianismo e ao romance urbano nas suas mais amplas possibilidades de canalizar a influência de modelos europeus. Mas a fidelidade ao meio observado, enquanto linha programática do nacionalismo, significava também fator de limitação, uma vez que esse meio seria pouco estimulante a uma perspectiva mais objetiva. Tal peculiaridade aparece na visão que o autor apresenta do "contador de casos" Bernardo Guimarães. Tendo como eixo a observação da vida sertaneja ajustada ao mundo natural, os romances do autor de $O$ seminarista obedeceriam a uma impressão de ordem plástica, em que a paisagem surge como cenário qualitativo:

Os seus livros começam por uma situação de equilíbrio e bonança, definida principalmente pela descrição eufórica da paisagem em que se vai desenrolar a ação; a partir daí, procura surpreender no 
personagem o nascimento da paixão, cujo percurso e estouro descreverá, mostrando que a euforia inicial é como a placidez aparente do sertão e do sertanejo (CANDIDO, 1975, p. 238).

A região seria, pois, um quadro natural e social. Estendendo essa percepção a José de Alencar, Visconde de Taunay e Franklin Távora, Antonio Candido observa que vários dos livros desses autores "[...] são construídos em torno de um problema humano, individual ou social, e que, a despeito de todo o pitoresco, os personagens existem independentemente das peculiaridades regionais" (CANDIDO, 1975, p. 212). Tratava-se da "humanidade da narrativa", embora superficial e, portanto, ainda insuficiente para a maturidade do romance brasileiro.

Em "literatura e subdesenvolvimento" (CANDIDO, 1987, p. 140162), essa etapa necessária da literatura que tomava consciência do país novo, selecionando e incorporando para a expressão literária temas da realidade local, recebe o nome de "regionalismo pitoresco". A supervalorização dos aspectos regionais era, segundo o estudo citado, um meio de a literatura compensar o atraso material e a debilidade das instituições, na fase em que a ideia de pátria se vinculava estreitamente à de natureza.

De um modo geral, Antonio Candido percebe o regionalismo dos românticos como um instrumento de descoberta (e não como um subproduto sem maiores consequências, mesmo considerando a inabilidade técnica ou a visão elementar dos seus autores ${ }^{4}$ ). Na percepção do autor de Formação da literatura brasileira, essa "descrição típica da vida e do homem nas regiões afastadas" obteve momentos de um equilíbrio até então desconhecido, a exemplo de Inocência, livro no qual Taunay fundiu harmonicamente "[...] a intensidade emocional, o pitoresco regionalista, a fidelidade da observação e a felicidade do estilo" (CANDIDO, 1975, p. 296).

A perspectiva regionalista não aparece, todavia, de forma homogênea ao longo da história da literatura brasileira. Um dos seus frutos, a chamada "literatura sertaneja", teria como característica os seguintes aspectos:

${ }^{4}$ Como esclarece ao comparar Guimarães Rosa com predecessores que praticaram uma ficção regionalista “[...] feita quase sempre 'de fora para dentro' e revelando escritor simpático, compreensivo, mas separado da realidade essencial do mundo que descreve; e que enxerta num contexto erudito elementos mais ou menos bem apreendidos da personalidade, costumes, linguagem do homem rústico, obtendo montagens, não a integração necessária ao pleno efeito da obra de arte" (CANDIDO, 2002, p. 191, grifo do autor). 
[...] tende a anular o aspecto humano, em benefício de um pitoresco que se estende também à fala e ao gesto, tratando o homem como peça da paisagem, envolvendo ambos no mesmo tom de exotismo. É uma verdadeira alienação do homem dentro da literatura, uma reificação da sua substância espiritual, até pô-la no mesmo pé que as árvores e os cavalos, para deleite estético do homem da cidade (CANDIDO, 1975, p. 212-213).

A leitura em questão estabelece uma diferença qualitativa entre o regionalismo dos românticos e a literatura sertaneja, sobretudo no que se refere à percepção da "humanidade da narrativa". Em termos de formação do sistema literário, o regionalismo exerceu papel fundamental contribuindo, inclusive, para a definição do que seria o específico da literatura brasileira na etapa final do processo formativo. Neste sentido, o autor de Formação da literatura brasileira identifica, no final do segundo volume do estudo, após analisar os ataques de Franklin Távora a José de Alencar, a tomada de consciência deste último sobre o universo do escritor brasileiro.

O salto qualitativo de José de Alencar repercutiria imediatamente no jovem Machado de Assis, em quem Antonio Candido se apoia para concluir a sua pesquisa. Ao citar o seguinte trecho de "Instinto de nacionalidade", o estudioso da formação do sistema literário nacional parece reforçar o que Alencar reconheceu no que diz respeito à superação do regionalismo que praticara $^{6}$ :

Não há dúvida que uma literatura, sobretudo uma literatura nascente, deve principalmente alimentar-se dos assuntos que lhe oferece a sua região; mas não estabeleçamos doutrinas tão absolutas que a empobreçam. O que se deve exigir do escritor, antes de tudo, é certo sentimento íntimo, que o torne homem do seu tempo e do seu país, ainda quando trate de assuntos remotos no tempo e no espaço (MACHADO DE ASSIS, apud CANDIDO, 1975 , p. 368-369).

O aspecto da "humanidade da narrativa" pela via do regionalismo reapareceria no segundo momento decisivo da literatura brasileira, o

${ }^{5}$ Em "Literatura e Cultura de 1900 a 1945", ao analisar o período pós-romântico da literatura brasileira, caracterizado como "literatura de permanência", o autor situa o "conto sertanejo": "Gênero artificial e pretensioso, criando um sentimento subalterno e fácil de condescendência em relação ao próprio país, a pretexto de amor da terra, ilustra bem a posição dessa fase que procurava, na sua vocação cosmopolita, um meio de encarar com olhos europeus as nossas realidades mais típicas. Forneceu-lho o 'conto sertanejo', que tratou o homem rural do ângulo pitoresco, sentimental e jocoso, favorecendo a seu respeito idéias-feitas perigosas tanto do ponto de vista social quanto, sobretudo, estético" (CANDIDO, 1980, p. 113-114).

6 " [...] a legitimidade nacional das pesquisas essenciais do romance, liberto do pitoresco em benefício do humano social e psicológico; do humano contemporâneo, que nos toca de perto e envolve a sensibilidade com os seus problemas" (CANDIDO, 1975, p. 368). 
Modernismo, com o chamado "romance nordestino". Mas a sua reaparição só foi possível, entre outros fatores, graças a um processo de amadurecimento da problemática analisada por Antonio Candido ao estudar o processo formativo do sistema literário nacional.

\section{A “MoRTE” Do Regionalismo}

Para analisar a permanência do tema regional na literatura brasileira após a consolidação do sistema literário, Antonio Candido insere a questão em alguns ensaios que discutem, entre outros assuntos, a tendência da crítica contemporânea de decretar a "morte do regionalismo" tanto na literatura brasileira quanto na chamada literatura latino-americana.

Em "Literatura e subdesenvolvimento", o termo em questão "[...] abrange toda a ficção vinculada à descrição das regiões e dos costumes rurais desde o Romantismo" (CANDIDO, 1987, p. 157). Encarado como um tema, deve ser percebido no âmbito da atuação que as condições econômicas e sociais exercem sobre a sua escolha. Antonio Candido esclarece que o regionalismo permanece como uma força estimulante na literatura, uma vez que a situação de atraso econômico e social invade o campo da consciência e da sensibilidade do escritor, "propondo sugestões, erigindo-se em assunto que é impossível evitar". Assim, no período do Modernismo, sobretudo o que se seguiu após a revolução de 1930, o regionalismo funcionou como "[...] presciência e depois consciência da crise, motivando o documentário e, com o sentimento de urgência, o empenho político" (CANDIDO, 1987, p. 156 e 158). Superado o regionalismo pitoresco vinculado ao otimismo patriótico dos românticos, o tema regional se transformou; mas permaneceu, uma vez que o atraso básico do país periférico se prolongava no século XX:

Na fase de pré-consciência do subdesenvolvimento, ali pelos anos de 1930 e 1940, tivemos o regionalismo problemático, que se chamou de "romance social", "indigenismo", "romance do Nordeste", segundo os países, e, sem ser exclusivamente regional, o é em boa parte. Ele nos interessa mais, por ter sido um precursor da consciência de subdesenvolvimento [...] (CANDIDO, 1987, p. 160).

Ao analisar as relações entre a revolução de 1930 e a cultura, Antonio Candido observa que, após aquele momento revolucionário, a cultura brasileira passou por um processo de unificação, dispondo em nova 
configuração elementos até então dispersos ${ }^{7}$, ou seja, "projetando na escala da Nação fatos que antes ocorriam no âmbito das regiões" (CANDIDO, 1987, p. 181-182). No âmbito da literatura, ele distingue, entre outros traços, o alargamento das "literaturas regionais" à escala nacional, num movimento que permitiria ao leitor "uma visão renovada, não-convencional, do seu país, visto como um conjunto diversificado mas solidário" (CANDIDO, 1987, p. 187). $\mathrm{O}$ "romance do Nordeste" seria, pois, coextensivo à própria literatura brasileira ${ }^{8}$ :

A sua voga provém em parte do fato de radicar na linha da ficção regional (embora não "regionalista", no sentido pitoresco), feita agora com uma liberdade de narração e linguagem antes desconhecida. Mas deriva também do fato de todo o País ter tomado consciência de uma parte vital, o Nordeste, representado na sua realidade viva pela literatura (CANDIDO, 1987, p. 187).

Na fase em questão, a "consciência social" dos escritores foi determinante, pois surgiu como um problema a ser enfrentado no terreno da elaboração literária: "organização estética", "elaboração formal" constituíam um paradigma que, para os escritores, não poderia atrapalhar o impacto humano da obra. Segundo Antonio Candido, poucos tiveram a capacidade de resolver o problema, e pouquíssimos puderam unir a formulação crítica adequada à realização correta:

O que houve mais foi preocupação de discutir a pertinência dos temas e das atitudes ideológicas, quase ninguém percebendo como uma coisa e outra dependem da elaboração formal (estrutural e estilística), chave do acerto entre arte e literatura (CANDIDO, 1987, p. 197).

Na sua segunda fase, as tendências regionalistas reapareciam já sublimadas e como transfiguradas pelo realismo social, atingindo o nível das obras significativas - fenômeno até então inédito, pois os melhores

${ }^{7}$ Ao ler Macunaíma como expressão de uma "entidade nacional brasileira", Leyla Perrone-Moisés observa que tal processo já estava implicado na obra de Mário de Andrade: "Vale lembrar que até 1930 a economia brasileira se baseava em plantações agrícolas voltadas para o mercado internacional, sem que houvesse comunicação entre elas. As diferentes regiões brasileiras tinham estruturas políticas autônomas, e o Estado era muito fraco para integrá-las. A diversidade social e cultural das regiões era também um entrave para a formação de uma 'consciência nacional'. M.A. aspirava a essa união nacional por meio de uma 'desregionalização', que em seu momento só podia ser concebida como ficção” (PERRONE-MOISÉS, 2007, p. 194).

${ }^{8}$ Para uma discussão específica sobre o conjunto da produção de romances do período, cf. o estudo Uma história do romance de 30 (BUENO, 2006). 
produtos da ficção brasileira foram, segundo Antonio Candido, sempre urbanos $^{9}$. Seguindo a linha geral do Modernismo (regionalista, folclórico, libertino, populista), os romancistas de 30 buscavam, com a humanidade singular dos protagonistas das suas narrativas, "[...] construir uma literatura universalmente válida [...] por meio de uma intransigente fidelidade ao local" (CANDIDO, 1980, p. 126). Mas a década seguinte, quando o "local" seria visto como pitoresco e extraliterário, enfraqueceria as tendências regionalistas vinculadas ao Modernismo. A partir de então, o qualificativo de regionalismo apareceria mais como uma pecha.

Segundo o autor de "Literatura e subdesenvolvimento", o fim do regionalismo não impediu, porém, que a dimensão regional continuasse presente em muitas obras da maior importância, embora sem qualquer caráter de tendência impositiva, ou de requisito duma equivocada consciência nacional:

O que vemos agora, sob este aspecto, é uma florada novelística marcada pelo refinamento técnico, graças ao qual as regiões se transfiguram e os seus contornos humanos se subvertem, levando os traços antes pitorescos a se descarnarem e adquirirem universalidade (CANDIDO, 1987, p. 161).

Neste sentido, o regionalismo sobrevive como uma tendência que se nutre da tensão dialética entre o local e o universal. o crítico apreende essa tensão quando verifica que o fim do regionalismo significou também o descarte do sentimentalismo e da retórica, ao mesmo tempo em que acontecia, na narrativa, o aproveitamento do que antes era a própria substância do nativismo, do exotismo e do documentário social. Com raízes no campo extraliterário - as condições dramáticas peculiares do atraso -, as tendências regionalistas aparecem estilizadas e graças ao dado objetivo da realidade que interfere "na seleção dos temas e dos assuntos, bem como na própria elaboração da linguagem"10 (CANDIDO, 1987, p. 162).

${ }^{9} \mathrm{Cf}$. também o estudo O romance da urbanização (GIL, 1999).

${ }^{10} \mathrm{Em}$ "A literatura e a formação do homem", Antonio Candido reitera: "[...] é forçoso convir que, justamente porque a literatura desempenha funções na vida da sociedade, não depende apenas da opinião crítica que o Regionalismo exista ou deixe de existir. Ele existiu, existe e existirá enquanto houver condições como as do subdesenvolvimento, que forçam o escritor a focalizar como tema as culturas rústicas mais ou menos à margem da cultura urbana. o que acontece é que ele vai modificando e adaptando, superando as formas mais grosseiras até dar a impressão de que se dissolveu na generalidade dos temas universais, como é normal em toda obra bem-feita. E pode mesmo chegar à etapa onde os temas rurais são tratados com um requinte que em geral só é dispensado aos temas urbanos, como é o caso de Guimarães Rosa [...]" (CANDIDO, 2002, p. 86-87). No mesmo estudo, destaca-se interessante exame da tensão entre tema e linguagem no regionalismo. 
A essa terceira fase, na qual a narrativa se nutre das técnicas advindas das vanguardas históricas, Antonio Candido chama de superregionalista ${ }^{11}$ : "Deste super-regionalismo é tributária, no Brasil, a obra revolucionária de Guimarães Rosa, solidamente plantada no que se poderia chamar de a universalidade da região" (CANDIDO, 1987, p. 162).

Na recepção a Sagarana (1946) e a Grande sertão: veredas (1956), o crítico identifica o salto qualitativo de Guimarães Rosa em um momento histórico e em relação aos regionalistas predecessores:

Mas Sagarana não vale apenas na medida em que nos traz um certo sabor regional, mas na medida em que constrói um certo sabor regional, isto é, em que transcende a região. A província do sr. Guimarães Rosa, no caso Minas, é menos uma região do Brasil do que uma região da arte, com detalhes e locuções e vocabulário e geografia cosidos de maneira por vezes quase irreal, tamanha é a concentração com que trabalha o autor (CANDIDO, 2002, p. 185, grifos do autor).

Em Grande sertão: veredas, o aproveitamento literário do material observado na vida sertaneja se dá "de dentro para fora", no espírito, mais que na forma. $\mathrm{O}$ autor inventa, como se, havendo descoberto as leis mentais e sociais do mundo que descreve, fundisse num grande bloco um idioma e situações artificiais, embora regidos por acontecimentos e princípios expressionais potencialmente contidos no que registrou e sentiu (CANDIDO, 2002, p. 191, grifos do autor).

O salto qualitativo da transcendência do regional seria alcançado "graças à incorporação em valores universais de humanidade e tensão criadora". O "homem perene" se faz, pois, sentir na obra de Guimarães Rosa. Comparado aos predecessores, ele:

[...] parece ter querido mostrar a possibilidade de chegar à vitória partindo de uma série de condições [temática, exotismo do léxico, tendência descritiva, capricho meio oratório do estilo] que conduzem, geralmente, ao fracasso. Ou melhor: todos os fracassos dos seus predecessores se transformaram, em suas mãos, noutros tantos fatores de vitória (CANDIDO, 2002, p. 187).

A trajetória da leitura apresentada até aqui permite chegar à conclusão de que a obra de Guimarães Rosa representa, na visão de Antonio Candido, um ponto de chegada das diversas tendências regionalistas, com a superação de uma tradição inserida no sistema literário nacional e sempre deformada pela dominante construtiva da tradição do romance urbano. Mas

11 “[...] pensando em surrealismo, ou super-realismo" (CANDIDO, 1987, p. 161). 
a justificativa para o nascimento e a morte do regionalismo não residiria apenas no âmbito do sistema literário. Tratar-se-ia, antes, de uma invenção radicada no processo social brasileiro.

\section{A TendÊncia Genealógica do Regionalismo}

Em "Literatura de dois gumes", Antonio Candido se refere à "tendência genealógica" designando a "interpretação ideologicamente dirigida do passado com o intuito de justificar a situação presente", tendência que explicaria o modo como, no período colonial, "[...] a inteligência escolheu aspectos adequados para criar um meio natural representado na literatura e dando forma ao sentimento" (CANDIDO, 1987, p. 172-173, grifo do autor). Naquele período, a idealização do índio, a sua invenção, consistiu em "[...] escolher no passado local os elementos adequados a uma visão que de certo modo é nativista, mas procura se aproximar o mais possível dos ideais e normas européias". Inventava-se "[...] um passado que já fosse nacional, marcando desde cedo a diferença em relação à mãe-pátria” (CANDIDO, 1987, p. 173 e 175).

Com base no exposto, é possível estabelecer uma relação entre a "tendência genealógica" que inventou o indianismo e as tentativas programáticas de dar visibilidade ao regionalismo no Brasil. Acreditamos que essas tentativas também significaram modos de invenção, embora em perspectivas diferentes daquela do indianismo, que foi amplamente incorporado pela coletividade e pelas elites dirigentes da jovem nação.

No caso dos regionalismos, tratava-se de movimentos de reação a uma ordem unificadora dominante, vitoriosa e irreversível, contrária à existência dos programas localistas. Na história da literatura brasileira, há pelo menos dois casos exemplares de regionalismos, digamos "derrotados", mas com enorme poder de interferência no programa dos movimentos que, em princípio, lhes eram antagônicos: o regionalismo defendido por Franklin Távora e o regionalismo defendido por Gilberto Freyre, ambos na região Nordeste.

Ambos os programas tinham por base um passado de glória que era reivindicado para justificar a verdade idealizada: para Távora, um Norte mais brasileiro do que o resto do país, correspondendo praticamente à nação que poderia ter surgido da Confederação do Equador ${ }^{12}$; para Gilberto Freyre, um Nordeste à imagem do mundo açucareiro pernambucano.

12 Antonio Candido chega a levantar a hipótese de que o regionalismo poderia corresponder, em alguns casos, a literaturas nacionais atrofiadas (embora signifique, "no plano geral unificador, uma procura dos elementos específicos da nacionalidade”). (Cf. CANDIDO, 1987, p. 202). 
No caso do primeiro grande momento da literatura brasileira, o Romantismo, Antonio Candido lembra, contudo:

[...] antes mesmo do indianismo e do regionalismo, a ficção brasileira, desde os anos de 1840 , se orientou para a outra vertente de identificação nacional através da literatura: a descrição da vida nas cidades grandes, sobretudo o Rio de Janeiro e áreas de influência, o que sobrepunha à diversidade do pitoresco regional uma visão unificadora (CANDIDO, 1987, p. 203).

No caso do segundo grande momento, vale salientar que o programa regionalista de Gilberto Freyre se diluiu no nível das conquistas modernistas, de forma bastante complexa e, sobretudo, no plano das obras literárias e do ensaio histórico-social daí resultantes. Para a história da literatura brasileira, o decisivo foram as contribuições do Modernismo que permitiram: "a destruição dos tabus formais, a libertação do idioma literário, a paixão pelo dado folclórico, a busca do espírito popular, a irreverência como atitude" (CANDIDO, 1980, p. 135) ${ }^{13}$.

Como se percebe, não é exclusivamente a força dos programas mais próximos da categoria da invenção, no sentido exposto aqui - que escreve a história da literatura, uma vez que as obras - mais próximas de uma categoria que poderia se chamar de realização inventiva - ganham sentidos que superam as intenções dos movimentos nos quais foram geradas. Exemplo disso é o caso do romance de 30 , nordestino, nas suas vinculações com o regionalismo e com o Modernismo. E como superação da problemática, digamos, obsessiva da tendência genealógica que criou o regionalismo, a obra de Guimarães Rosa pode representar uma espécie de apropriação de toda a tradição do particularismo para, enfim, diluir os seus termos no processo que o privilegiado leitor que examinamos neste trabalho chamou de "incorporação em valores universais de humanidade e tensão criadora" - a apropriação do que for necessário à apreensão da chamada "humanidade da literatura", incluindo-se, no caso brasileiro, as obsessões localistas. No que tange à vitalidade do regionalismo na literatura brasileira, a síntese operada na leitura de Antonio Candido parece apontar para a confirmação das suas teses iniciais do Formação, que se atualiza em texto de $1979^{14}$ :

${ }^{13}$ Em "Literatura e cultura de 1900 a 1945", a obra do escritor pernambucano é vista no contexto do Modernismo, especialmente pelo fato de "estudar com livre fantasia o papel do negro, do índio e do colonizador na formação de uma sociedade ajustada às condições do meio tropical e da economia latifundiária". Mesmo considerando a perspectiva regionalista contrária ao programa do Modernismo, Antonio Candido avalia: "Um autor como Gilberto Freyre, que parece hoje um sociólogo conservador, significou então uma força poderosa de crítica social, com a desabusada liberdade das suas interpretações” (CANDIDO, 1980, p. 124 e 135).

14 "A nova narrativa", comunicação apresentada ao "Encontro sobre ficção latinoamericana contemporânea" no Woodrow Wilson Center for Sholars, Washington, e publicada em vários periódicos e livros, a exemplo de A educação pela noite (1987), que apresenta nota sobre o texto à p. 217. 
Estas considerações aparentemente intempestivas são feitas com o intuito de lembrar que na ficção brasileira o regional, o pitoresco campestre, o peculiar que destaca e isola, nunca foi elemento central e decisivo; que desde cedo houve nela uma certa opção estética pelas formas urbanas, universalizantes, que ressaltam o vínculo com os problemas supra-regionais e supranacionais; e que houve sempre uma espécie de jogo dialético deste geral com aquele particular, de tal modo que as fortes tendências centrífugas (correspondendo no limite a quase literaturas autônomas atrofiadas) se compóem a cada instante com as tendências centrípetas (correspondendo à força histórica da unificação política) (CANDIDO, 1987, p. 203).

\title{
RESUMO
}

Análise da noção de regionalismo na obra de Antonio Candido, tomando como ponto de partida a leitura do livro Formação da literatura brasileira, onde o autor apreende o surgimento da tradição regionalista como uma das tendências do movimento romântico e como um instrumento de descoberta do país novo. A perspectiva regionalista é apresentada nas suas várias fases ao longo da história do sistema literário brasileiro, de forma não homogênea e sempre reagindo de forma problemática aos processos unificadores nacionais. No debate sobre a permanência do regionalismo na literatura brasileira, destacase a leitura da obra de Guimarães Rosa como um modo de transcendência do regional "graças à incorporação em valores universais de humanidade e tensão criadora”. Esta análise propõe, enfim, o estabelecimento de uma relação entre a "tendência genealógica" que inventou o indianismo e as tentativas programáticas de dar visibilidade ao regionalismo no Brasil.

Palavras-chave: regionalismo; tradição; sistema literário.

\begin{abstract}
Analysis of the concept of regionalism based in Antonio Candido, having as starting point the reading of the book Formação da literatura brasileira, in which the author apprehends the sprouting of the regionalistic tradition as one of the trends of the romantic movement and as an instrument of discovery of the new country. The regionalistic perspective
\end{abstract}


is presented in its various stages of the history of the Brazilian literary system, in a non-homogeneous form and always reacting of a problematic way to the national unifying processes. In the debate about the permanence of the regionalism in Brazilian literature, it is distinguished the reading of the work of Guimarães Rosa as a way of transcendence of the regional "thanks to the incorporation in the universal values of the humanity and to the creative tension". This analysis considers, at last, the establishment of a relationship between the "genealogical trend" that invented the indianism and the programmatical attempts to give visibility to the regionalism in Brazil.

Key-words: regionalism; tradition; literary system.

\section{REFERÊNCIAS}

AZEVÊDo, Neroaldo Pontes. de. Modernismo e regionalismo: os anos 20 em Pernambuco. João Pessoa: Secretaria de Educação e Cultura da Paraíba, 1984.

BUENO, Luís. Uma história do romance de 30. São Paulo: Editora da Universidade de São Paulo; Campinas: Editora da Unicamp, 2006.

CANDIDO, Antonio. Literatura e cultura de 1900 a 1945. In: . Literatura e sociedade.

5. ed. Rio de Janeiro: Ed. Nacional, 1980. p. 109-138.

. Formação da literatura brasileira: momentos decisivos. 5. ed. Belo Horizonte; São Paulo: Itatiaia: Ed. da Universidade de São Paulo, 1975. v. 2.

. A educação pela noite e outros ensaios. São Paulo: Ática, 1987.

. Textos de intervenção. Seleção, apresentação e notas de: Vinícius Dantas. São Paulo: Duas Cidades: Ed. 34, 2002.

D'ANDREA, Moema Selma. A tradição re(des)coberta: Gilberto Freyre e a literatura regionalista. Campinas: Editora da Unicamp, 1992.

GIL, Fernando Cerisara. O romance da urbanização. Porto Alegre: EDIPUCRS, 1999.

MELLO, Evaldo Cabral de. A ferida de Narciso: ensaio de história regional. São Paulo: Editora SENAC, 2001.

PALLARES-BURQUE, Maria Lúcia Garcia. Gilberto Freyre: um vitoriano dos trópicos. São Paulo: Editora da Unesp, 2005.

PERRONE-MOISÉS, Leyla. Macunaíma e a "entidade nacional brasileira". In: . Vira e mexe, nacionalismo: paradoxos do nacionalismo literário. São Paulo: Companhia das Letras, 2007. p. 188-209.

Submetido em: 20/03/2008.

Aceito em: 25/11/2008. 